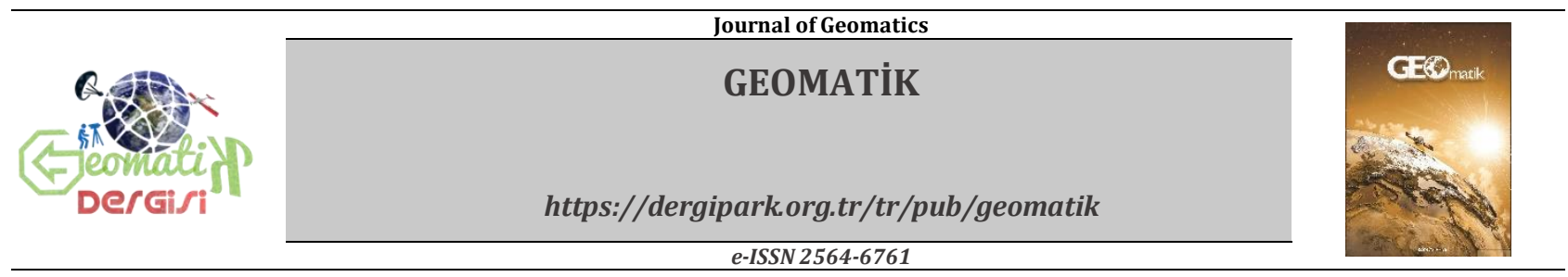

\title{
Konya Kapalı Havzası Obruk Envanter Bilgi Sisteminin Oluşturulması
}

\author{
Osman Orhan*1, Osman Sami Kırtıloğlu², Murat Yakar³ \\ ${ }^{1}$ Konya Teknik Üniversitesi, Mühendislik ve Doğa Bilimleri Fakültesi, Harita Mühendisliği Bölümü, Konya, Türkiye \\ 2̇̇zmir Kâtip Çelebi Üniversitesi, Mühendislik Fakültesi, Harita Mühendisliği Bölümü, İzmir, Türkiye \\ ${ }_{3}^{3}$ Mersin Üniversitesi, Mühendislik Fakültesi, Harita Mühendisliği Bölümü, Mersin, Türkiye
}

Anahtar Kelimeler
Obruk
Karapınar
KKH
Envanter Bilgi Sistemi

\section{ÖZ}

Ülkemizde özellikle Konya Kapalı Havzası'nda 2000 yılından sonra oluşumları hızla artan karstik yer şekillerinden olan obruk oluşumları jeolojik, iklimsel ve antropojenik etkilere bağlı olarak meydana gelmektedir. Bu çalışmada, obruk oluşumlarının yol açtığ maddi/manevi kayıpların azaltılması ve obrukların mekânsal dağılımını kontrol eden çevresel faktörlerin daha iyi anlaşılmasını sağlamak amacı ile web ve bulut tabanlı haritalama servisleri kullanılarak obruk envanter bilgi sisteminin olușturulmuștur.

\section{Creation of The Konya Closed Basin Sinkhole Inventory Information System}

\author{
Keywords \\ Sinkhole \\ Karapınar \\ KCB \\ Inventory Information System
}

\begin{abstract}
In our country, especially in the Konya Closed Basin, the karstic formations, which have been rapidly increasing after 2000 , occur due to geological, climatic and anthropogenic effects. In this study, sinkhole inventory information system has been established by using the web and cloud-based mapping services in order to reduce the material / spiritual losses caused by sinkhole formation and to better understand the environmental factors controlling the spatial distribution of sinkhole.
\end{abstract}

ORHAN, O , KIRTILOĞLU, O , YAKAR, M . (2020). Konya Kapalı Havzası Obruk Envanter Bilgi Sisteminin Oluşturulması. Geomatik, 5 (2), 81-90 . DOI: 10.29128/geomatik.577167 Retrieved from https://dergipark.org.tr/tr/pub/geomatik/issue/52495/577167 


\section{GíRiş}

Doğal afetler genellikle doğanın genel işleyişi sırasında veya insan faktörü sayesinde tetiklenen ve sonrasında fiziksel, sosyal ve ekonomik kayılara neden olabilecek tehlikeli ve genellikle büyük çaplı olay olarak tanımlanır. Doğal afetler, jeolojik ve meteorolojik afet türlerini ve çevresel sorunları içinde barındırır. Örneğin; sel ve sel felaketleri, kuraklık, orman yangınları, tropikal siklonlar, kasırgalar ve şiddetli firtınaları içeren meteorolojik afetler, tektonik hareketler, depremler, tsunamiler, volkanlar, patlayıcı krater gölleri, heyelanlar, obruklar, çamur selleri, erozyon, sediment birikimi gibi jeolojik afetler ve ayrıca savaşlar, yer altı sularının ve petrolün vahşi kullanımı, madencilik, arazi bozulması gibi insan kaynaklı meydana gelen afetleri içerir.

İnsan kaynaklı olan afetlerin temel sebebi aslında dünya nüfusunun hızlı artışı ve buna bağlı olarak barınmak ve gündelik ihtiyaçları karşılamak için doğal kaynakların kontrolsüz şekilde kullanılmasıdır. Bunun sonucunda doğal alanlar yerleşim yerlerine çevrilmekte, nüfus artışına bağlı olarak endüstriyel alanlar artmakta, bunların ihtiyaç duyduğu yeraltı kaynakları kontrolsüz kullanılmakta ve bunlarla beraber bölgedeki birçok kullanılabilir su kaynağı hızla azalmaktadır. Böylesi insan kaynaklı etkiler ekosistemin bozulmasına, iklim değişikliğine ve dünyadaki yaşamın devamlllığı için en önemli doğal kaynak olan su miktarının azalmasına neden olmaktadır. Birleşmiş milletlere göre dünyanın sahip olduğu su miktarının sadece \%2,5'lik kısmı canlılar için uygundur ve bu suyun \%68,9'luk kısmı buzullarda olduğundan kullanılamaz durumdadır. Geri kalan suyun ise \%30,8'lik kısmı yeraltı suyu, $\% 0,3$ 'ü ise yüzey su kaynağı olarak bulunmaktadır. $\mathrm{Bu}$ durum sonucunda yeraltı suyu insanlar için en kolay ulaşılabilir kaynak olmuştur. Yeraltı suyunun; hızlı nüfus artışı, sanayileşme, tarım faaliyetleri için kontrolsüz kullanımı ve eksilen suyun küresel ısınmadan dolayı tamamlanmaması zemin çökmelerine ve obruk oluşumlarına neden olmaktadır (Awange, 2012; Galloway \& Burbey, 2011).

Genel olarak yeraltı suyunun, karbondioksit ile tepkimeye girmesi sonucu karbonik asit oluşturur. Bu karbonik asit kireç taşı, dolomit, marn gibi suda eriyebilen kayaçların yoğun bulunduğu bölgelerde zamanla bu kayaçları çözerek yer altında boşlukları ve mağara sistemlerini oluşturur. Mağaranın tavanında yer alan marnların ve killi karbonatların çok zayıf dayanımlı olmaları sonucu zaman içerisinde mağaranın tavanında bulunan yapının çökmesi ile obruk oluşumlarını meydana getirir.

Ülkemizde obruk oluşumları, Konya Kapalı Havzası'nda yer alan Obruk Platosunda çok sıklıkla görülmektedir. Özellikle son yıllarda yüzey deformasyonları ve obruk oluşumları bu platoda yer alan Karapınar ve çevresinde yoğunlaşmaktadır.

Günümüzde, obruk vb. oluşumların sonucu oluşabilecek olumsuz etkiler, insan hayatında ve sosyoekonomik anlamda çok büyük sonuçlar doğurmaktadır. Obruk sonrası olușan maddi ve manevi kayıplar gösteriyor ki, bu riskli bölgelerin iyi organize edilmiş bir eylem planına sahip olması ve bunun yanında obruğa karşı zarar azaltma çalışmalarını içeren afet ve risk yönetimine gerekli önemin verilmesi gerekmektedir. Bu kapsamda, güvenilir bir şekilde obruk risk alanlarının tanımlanması obruk envanterleri ile doğrudan ilişkilidir. Çünkü, obruk önceden hangi şartlar altında meydana gelmişse gelecekte de aynı şartlarda meydana gelmesi beklenir ve bu esasa göre yapılacak olan risk alanlarının tanımlanmasında obruk envanter haritaları temel alınır. Bu kapsamda envanter bilgilerinin doğru, güncel, güvenilir bir şekilde standart bir veri tabanında toplanması gerekmektedir.

Bu çalışma kapsamında, doğal afetlere (obruk, heyelan vb.) karşı zarar azaltma çalışmalarında ve afet ile ilgili eylem planlarının hazırlanmasında temel girdi parametresi olarak envanter haritalarına veya bilgi sistemlerine ihtiyaç duyulmaktadır. $\mathrm{Bu}$ çerçevede, KKH'nda meydana gelen obruklara ait envanter bilgi sistemi web ve bulut tabanlı haritalama servisleri kullanılarak oluşturulması hedeflenmiştir.

\section{2. ÇALIŞMA SAHASI ve ÖZELLIKLERI}

Alt-Havza sınırı Konya'ya bağlı olan Karapınar ilçesini ve çevresini içine alan $2420 \mathrm{~km} 2$ lik bir alanı oluşturmaktır. Havza sınırı AB-Hidro Drenaj Veritabanı (EU-Hydro Drainage Database) sistemi üzerinden elde edilmiştir. Havzanın sadece doğu bölgesinde $2022 \mathrm{~m}$ yüksekliğindeki Karacadağ bulunurken havzanın geri kalan bölgeleri düz veya düze yakın bir plato özelliği göstermektedir. Karacadağ’ın güneybatı eteklerinde, volkanik patlamalar sonucu oluşmuş iki patlama krateri olan Acıgöl ve Meke Gölü yer almaktadır. Bu havzanın ortalama denizden yüksekliği genel olarak $1.070 \mathrm{~m}$ civarındadır. Çalışma alanı coğrafi olarak $33^{\circ} 06^{\prime}$ ve $33^{\circ} 57^{\prime}$ doğu meridyenleri ve $37^{\circ} 30^{\prime}$ ve $38^{\circ} 02^{\prime}$ kuzey paralelleri arasında kalmaktadır. Konya Kapalı Havzasına iklimsel anlamda bakıldığında kapladığı alanın büyüklüğünden dolayı farklı iklimlerin (Güney kesimleri; Akdeniz İklimi, Kuzey kesimleri; Karasal iklim) hakim olduğu görülür. Konya Kapalı Havzası içerisinde kalan Karapınar çevresinde ise çöl iklimi hüküm sürmektedir ve bölge KKH'nın en az yağış alan bölgesidir. Devlet Meteoroloji İşleri kayıtlarına göre, Konya Kapalı Havzası genelinde ortalama toplam yağış miktarı 285 ile $755 \mathrm{~mm}$ arasında değişmektedir. Karapınar ve çevresi yıllık ortalama 285 mm (1964-2016) ile havzanın en az yağış alan bölgesidir. Karapınar ve çevresini kapsayan alt-havzada yaz aylarının (Temmuz, Ağustos) ortalama sıcaklıkların yüksek olması ve bu aylarda bölgeye düşen yağışın da az olmasından dolayı çevresel ve hidrolojik sorunlar ortaya çıkmaktadır. 


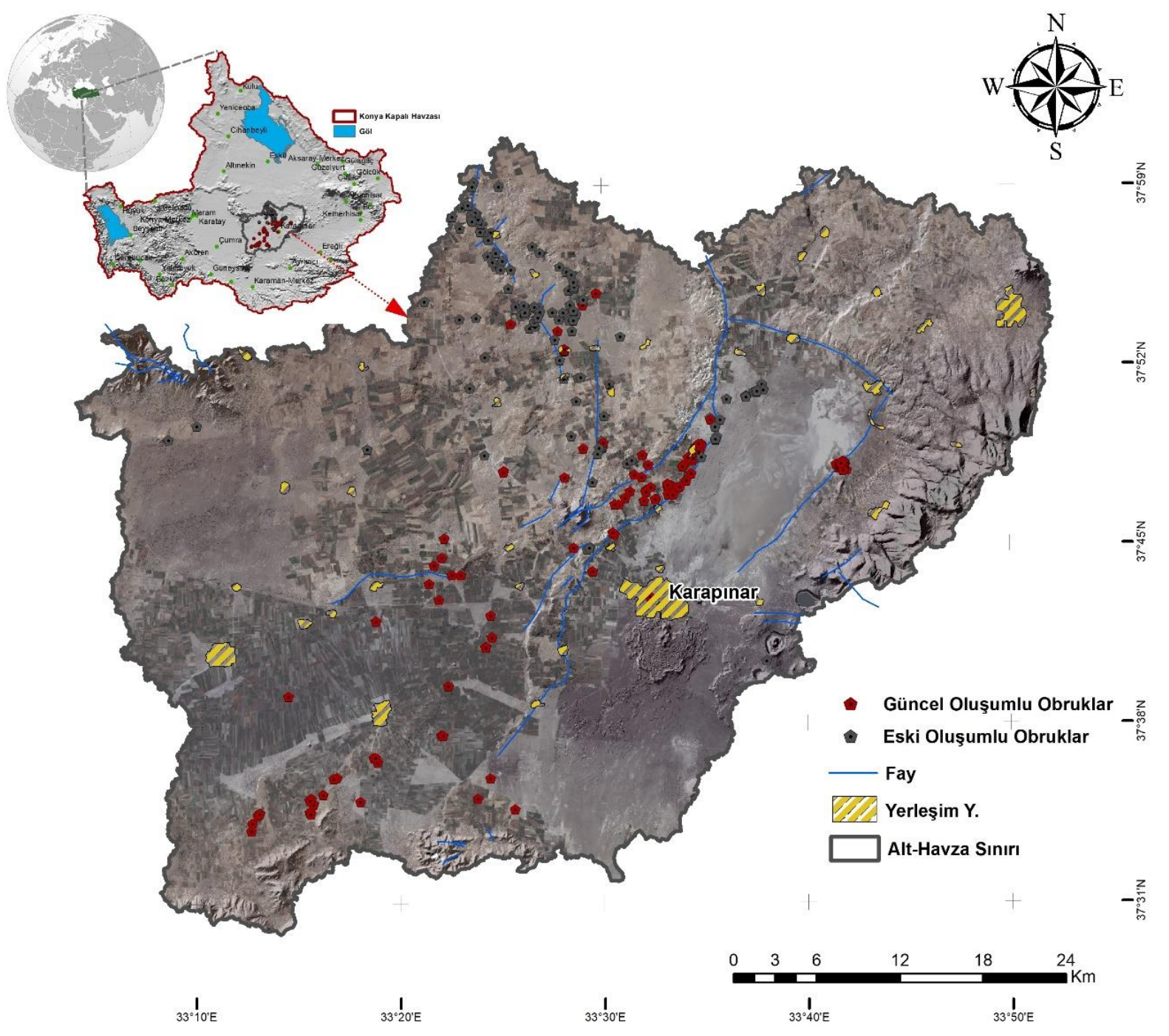

Şekil 1. Konya Kapalı Havzası ve Çalışma sahası

Karapınar, Türkiye'nin tarımsal ve ekonomik açıdan önemli bir üretim bölgesi olan Konya Kapalı Havzasının merkezinde yer almaktadır (Şekil 1). Bölgede, iklim özellikleri ile uyuşmayan yüksek miktarda su tüketimine sahip yoğun tarım faaliyetlerinin gerçekleștirilmesi, iklim değişikliği etkileri, bölgedeki yeraltı su kaynaklarının giderek azalıyor olması, yeraltından çekilen suyun yağışlar ile geri beslenememesi doğal yaşamı ve tarımın geleceğini tehdit altına almaktadır. Bu parametrelere Karapınar'ın jeolojik yapısı da eklendiği zaman bölgede zemin çökmeleri ve obruk oluşumları gibi çevresel sorunlar ortaya çıkmaktadır.

\section{OBRUK ENVANTER HARITALARI VE ARAZI ÇALIŞMASI}

Obruk Envanter Haritaları, obrukların belirli anda aniden çökme sonucu veya belirli bir zaman aralığında oturma eylemi şeklinde gerçekleşmesi sonucu, bunlarla ilgili envanter verilerinin toplanmasında ne zaman, nerede ve büyüklüğü nedir (Çap/Derinlik) gibi soruların cevaplarının kayıt altına alındığı veri tabanları ve bu verilerden üretilen haritalardır.
Karapınar ve çevresine ait güncel, doğru ve öznitelik bilgisi bakımından zengin (konum bilgisi, şekil, çap, derinlik, yerleşim yerlerine mesafe, oluşum yılı, bölgesi, vb. ) bir envanter bilgi sistemi, detaylı arazi çalışması, uydu görüntüleri ve bölgeye ait yüksek çözünürlüklü Sayısal Yükseklik Modeli'nin (SYM) incelenmesi sonucunda oluşturulmuştur. Arazi çalışması gerçekleştirilmeden önce, obruklara ait konumlar, bölgeye ait önceki çalışmalardan ve daha sonrasında sayısal yükseklik verileri ve güncel hava fotoğrafları ile belirlenmeye çalışılmıştır. Bozyiğit ve Tapur (2009) tarafindan 2013 yllında Konya ili kapsamında yapılan arazi çalışmasında 61'i eski ve 41'i yeni (1972-2013 arası) olmak üzere toplamda 102 obruk tespit edilmiştir. Bu 102 obruğun 84 tanesi Karapınar sınırları içerisinde yer almaktadır. Literatürden elde edilen bilgiler yardımcı bilgi olarak kullanılmıştır. Bölgedeki diğer obrukların konumları hakkında bilgi alabilmek için bölgeye ait elde edilen $30 \mathrm{~cm}$ çözünürlüğe sahip hava fotoğrafı görsel olarak yorumlanmış ve bu görüntüler üzerinden obruk olma ihtimali olan tüm yerler işaretlenmiştir. Arazi çalışmaları sırasında tüm bu noktalara gidilmiş, obruk olup olmadığı doğrulanmıș ve bölge halkı ile yapılan mülakatlar sonucunda farklı obruklara ait 
konum bilgileri elde edilmiştir. Literatür araştırmaları, 1/25000 ölçekli topoğrafik haritalar, Sayısal Yükseklik Modeli (SYM), hava fotoğrafları ve arazide gerçekleştirilen mülakatlar yardımı ile KKH sınırları içerisinde 362 Karapınar çalışma sahası içerisinde ise 332 obruk tespit edilmiştir. Ayrıca çalışma kapsamında her bir obruğa ait "obruk no, obruk ismi, bulunduğu bölge, çap, derinlik, şekil, yerleșim yerlerine uzaklık, konum bilgileri, su durumu, oluşum tarihi" gibi geometrik ve öznitelik bilgileri toplanmıștır.

\subsection{Web ve Bulut Tabanlı Haritalama Servisleri Kullanılarak Obruk Envanter Bilgi Sisteminin Oluşturulması}

Kablosuz ağların ve GPS özellikli cihazların hızlı gelişimi sayesinde Konum Tabanlı Servisler (KTS) günlük hayatlarımızda çok daha popüler ve önemli hale gelmektedir (Ilarri, Mena, \& Illarramendi, 2010) ve Google Haritalar kullanarak evimizden bir tren istasyonuna en kisa yolu hesaplamak, Uber yardımıyla en yakın taksinin konumunu belirlemek ve Yelp kullanarak belirlenen bir bölgedeki tüm restoranları sorgulamak gibi birçok işlemi gerçekleştirmemize imkan sağlamaktadır (Zhang, Liu, Liu, Mao, \& Li, 2017). Bulut tabanlı teknolojiler (BTT) elastik ve etkin maliyetli bir bilgi işlem altyapısı sağlamak için yeni bir paradigmayı ifade etmektedir (Vaquero, Rodero-Merino, Caceres, \& Lindner, 2008). Bulut teknolojilerinin tipik türleri arasında altyapı servisi, platform servisi ve yazılım servisi yer almaktadır (Mell \& Grance, 2010). Bulut teknolojilerinin diğer türleri ise veri tabanı servisi ya da ağ servisleridir. Nasıl isimlendirildiğine bakılmaksızın ölçeklenebilir veri tabanı yönetim sistemleri (VTYS) bulut teknolojileri altyapısının önemli bir parçasıdır (Agrawal, Das, \& El Abbadi, 2011). Mevcut birçok veri tabanı servisi, ya SQL (Structured Query Language) tabanlı ilişkisel VTYS'lere ya da Google BigTable gibi SQL içermeyen tablolar üzerine inşa edilmiştir (Stonebraker, 2010). Google Fusion Tables (GFT) gibi bazı servisler ise SQL içermeyen tablolarda SQL desteği vermek için bir denge kurmak çabası içerisindedir (Haselmann, Thies, \& Vossen, 2010). Obruk envanter bilgi sistemi verilerinin görselleştirilmesi için KTS’lerin, sisteme ait verilerin depolanması ve yönetimi için ise BTT'lerin kullanılması, maliyet ve emek açısından oldukça umut vadetmektedir.

Yukarıda ifade edilen web tabanlı teknolojiler kullanılarak bu çalışmada bir bulut tabanlı "Mashup" uygulaması oluşturulması amaçlanmıştır. İnternet teknolojisinin son 20 yılda çok yaygın olarak kullanılmaya başlanması ve web teknolojilerinde yaşanan gelişmeler "Web Mashup" teriminin ortaya çıkmasına zemin hazırlamıştır. Mashup, aslında bir müzik terimi olarak ortaya çıkmıștır. Farklı müzik parçalarının bir araya getirilerek kesintisiz olarak birleştirilmesi ya da karıştırılması ile oluşan yeni parçayı temsil etmektedir. Aynı durum video parçaları için de geçerlidir. Önceleri müzik ve video alanlarında kullanılan bu terim günümüzde web dünyasında yaşanan gelişmelere de bağlı olarak ikinci kuşak webin (Web 2.0) giderek yaygınlașan uygulamalarından biri olarak yerini almıştır. Web alanında bu terim birden fazla kaynaktan alınan içeriklerin, yeni bir hizmet oluşturmak amacıyla, tek bir grafik ara yüzde birleştirilmesi anlamında kullanılmaktadır.

Bulut tabanlı uygulamalar, bir veya daha fazla uzak sunucu arasında dağıtılan ve bir internet bağlantısı aracılığıyla son kullanıcılara erișilebilen, hem donanım hem de yazılım üzerinde çalışan programlardır. $\mathrm{Bu}$ uygulamalar, birçok nedenden ötürü son kullanıcılara yöneliktir. Kişisel bilgisayarlarda depolama alanından tasarruf etmeye yardımc olurlar, herhangi bir yerden bir internet bağlantısı ile erișilebilir durumdadır, yazılım yükleme ve güncelleme sorunlarını ortadan kaldırır, işletim sisteminden bağımsız olarak çalışırlar ve başkalarıyla işbirliğini (aynı dosya ya da veri tabanı üzerinde eş zamanlı çalışabilme) kolaylaştırırlar. Bulut tabanlı uygulamalar, pek çok avantajından ötürü hızlı bir şekilde geliștirilmekte ve dünyadaki yaşam biçimini değiştirmektedirler (Miller, 2008). Birçoğu ortak ihtiyaçları karşılamakla birlikte günlük olarak (Gmail, Facebook, LinkedIn, Google Drive, Dropbox, Microsoft OneDrive gibi) etkileşimde bulunulsa da, diğerleri çeşitli alanlarda, sektörlerde ve pazarlarda iş ihtiyaçlarını ve isteklerini karşılamak için geliştirilmektedir. $\mathrm{Bu}$ çalışmada oluşturulan Obruk Envanter Bilgi Sistemi, Konya-Karapınar bölgesinde oluşan obruklara ve bölge ile ilişkili diğer olgulara (jeolojik yapı, arazi kullanım verisi, fay hatları vb.) ait verilerin depolanması, yönetimi, ortak düzenlemeye imkân sağlaması, paydaşlarla paylaşılması ve görselleştirilmesi işlemlerini kapsamaktadır.

\subsubsection{Sistem altyapısı}

Birçok öncü bulut tabanlı veri yönetim sistemlerinde (örn., Google Drive, Box, Dropbox, Microsoft OneDrive) güncel eğilim, bulut teknolojisinin yalnızca veri depolama amacıyla değil, aynı zamanda depolanan verilerle etkileșime giren ve/veya depolanacak yeni veri üreten bulut bilgi işlem araçları sağlamaktır. Örneğin Google Drive, kullanıcılara belgeleri düzenlemek veya oluşturmak için bulut tabanlı bir kelime işlemci (Google Docs), etabloları düzenlemek veya oluşturmak için bir bulut tabanlı e-tablo (Google Sheets) ve bulut tabanlı bir sunum programı düzenlemek veya slayt gösterileri oluşturmak için bir araç (Google Slides) (Şekil 2) sunmaktadır (Covili, 2016).

$\mathrm{Bu}$ bulut bilgi işlem araçlarının temel bulut depolama sistemi ile entegrasyonu, büyük oranda veriyle işbirliği çabalarını teşvik edip kolaylaştıran özelliklerdir (Crawley, Ames, Li, \& Tarboton, 2017). 


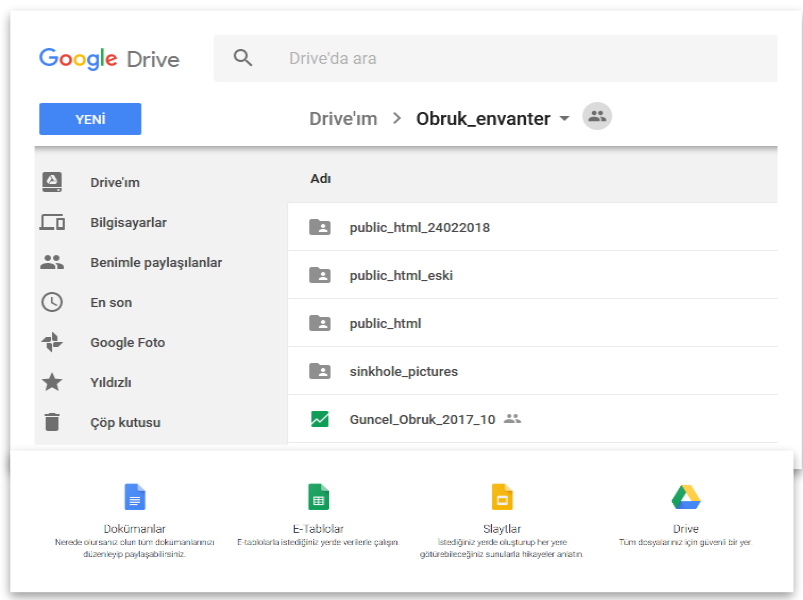

Şekil 2. Google Drive Klasörler ve GFT(üstte), Google Uygulamaları (altta)

\subsubsection{Google Fusion Tables}

Google Drive'ın kullanıclarına sunduğu bir diğer kullanışlı araç ise Google Fusion Tables (GFT) aracıdır. Kullanıcıların bulutta veri üzerinde işbirliği yapabilmelerini sağlayan GFT, işbirliğine dayalı bir araștırma platformu görevi görebilir. Kullanıcıların tablolarını grup üyeleri veya diğer katkıda bulunanlarla paylaşabilmesini, böylece başkalarının bunları görüntüleyebilmesi, yorumlayabilmesi ve düzenleyebilmesini sağlamaktadır. Google Haritalar ve Google Chart ile iyi entegre olan GFT, verilerin haritalar ve çizelgeler şeklinde anında görselleştirilmesini sağlar ve kullanıcıların Web ortamında görselleştirme sonuçlarını yayınlamalarını sağlar.

Buna ek olarak, GFT'deki veriler değiștiğinde haritalar ve grafikler otomatik olarak güncellenmektedir. GFT, farklı organizasyonlara veya kullanıcılara ait tabloları bir araya getirerek birden fazla kaynaktan veri entegrasyonunu destekler. Eşleşen bilgileri elde etmek ve toplam, ortalama, minimum ve maksimum fonksiyonları içeren verileri özetlemek için tabloları filtreleyerek veri araștırması ve analizini de destekler. GFT, bulut ortamında verileri yönetmek, görselleştirmek, araștırmak ve keşfetmek için bir araç sunar. Verileri tablolar, sütunlar, satırlar, şablonlar ve stiller aracılığıla yönetir (URL-1). Tablolar tablo ID numaraları ile adreslemektedir ve her bir tablo satır ve sütunlardan oluşmaktadır (Şekil 3).

Fusion Tables API (Application Programming Interface), kullanıcılara HTTP (Hyper Text Transfer Protocol) sorgularıyla tabloları kendi web tabanlı uygulamalarında kullanabilme imkanı sunmaktadır. Ayrıca GFT, Google Maps API ile birlikte kullanılarak Google Haritalar üzerine bir katman olarak eklenebilmektedir.

\begin{tabular}{|c|c|c|c|c|c|c|c|c|c|c|c|c|c|c|c|c|}
\hline \multirow{2}{*}{\multicolumn{3}{|c|}{$\begin{array}{c}\text { File Edit Tools Help } \equiv \text { Rows } 1 \text { v } \\
\text { Filter }- \text { No filters applied. Sorted by Region }\end{array}$}} & If Cards 1 & \multicolumn{13}{|l|}{ Pap of Lat } \\
\hline & & & & & & & & & & & & & & & & Not saving \\
\hline FID & Sinkhole No & Name & Town & Region & Year & Distance fro... & Shape & Diameter & Depth & Elevation & GW Stiation & Status & Information & Lat & Long & Lejant \\
\hline 158 & $\quad 151$ & Yarim Obrugu & Karapinar & Potur $Y$. & Eski Olusum & 30,7 & Elips & $490 \_420$ & 45 & 1060 & Susuz & Eski & & 37.96249478 & 33.39890704 & small_ \\
\hline 159 & 152 & Kurk Obruk & Karapinar & Potur Y. & Eski Olusum & 31,6 & Daire & $150 \_140$ & 18 & 1047 & Susuz & Eski & & 37.96610578 & 33.39779604 & 4 small_t \\
\hline 167 & 160 & Kayaalti Obrugu & Karapinar & Potur-Akobruk Y. & Eski Olusum & 33,5 & Elips & 403_270 & 10 & 1071 & Susuz & Eski & & 37.96425761 & 33.3774571 & small__ \\
\hline 267 & 263 & Kadinhani Hancerli Obrugu & Kadinhani & Pusat koyu & 2013 & 26 & Elips & $18 \_13$ & 7 & 1004 & Susuz & Yeni & & 38.40443896 & 32.19779624 & small_ \\
\hline 97 & 88 & Seyithaci Obrugu-X & Karapinar & Resadiye mh. Sh. Yay. & 2014 & 5 & Elips & $50 \_50$ & 1.5 & 1001 & Susuz & Yeni & & 37.81011315 & 33.57518803 & small_ \\
\hline 201 & 224 & Sekizli Kucuk Obruk & Karapinar & Sekizli Y. & 1983 & 18 & Daire & 16 & 3.5 & 1030 & Susuz & Yeni & & 37.87669109 & 33.46852072 & 2. small__t \\
\hline 202 & 219 & Sekizil Buyuk Obruk & Karapinar & Sekizli Y. & 1995 & 21,55 & Daire & 55 & 26 & 1028 & Susuz & Yeni & & 37.88961977 & 33.46365346 & small_ \\
\hline 96 & 87 & Seyithaci Obrugu-III & Karapinar & Seyithaci Y. & 2007 & 11,3 & Elips & $25-22$ & 4 & 1011 & Susuz & Yeni & & 37.81361444 & 33.57615194 & small_ \\
\hline 98 & 89 & Seyithaci Obrugu-ll & Karapinar & Seyithaci Y. & 2007 & 10,85 & Elips & $16 \_13$ & 3 & 1010 & Susuz & Yeni & & 37.80971116 & 33.57525806 & small_t \\
\hline 106 & 97 & Seyithaci Obrugu-IV & Karapinar & Seyithaci Y. & 2008 & 12 & Elips & $17-15$ & 2 & 1009 & Susuz & Yeni & & 37.81593107 & 33.581212 & small_ \\
\hline 107 & 98 & Seyithaci Obrugu-1 & Karapinat & Seyithaci Y. & 2007 & 12,1 & Elips & 15 & 1 & 1011 & Susuz & Yeni & & 37.81535441 & 33.58092305 & small_ \\
\hline 108 & 99 & Seyithaci Obrugu-V & Karapinar & Seyithaci Y. & 2008 & 12,1 & Elips & $14-12$ & 4 & 1009 & Susuz & Yeni & & 37.81514741 & 33.58132044 & small_t \\
\hline 109 & 100 & Seyithaci Obrugu-VI & Karapinar & Seyithaci Y. & 2008 & 11 & Daire & 6 & 6 & 1012 & Susuz & Yeni & & 37.80498825 & 33.57370678 & small_e \\
\hline 115 & 106 & Seyithaci Obrugu-VII & Karapinar & Seyithaci Y. & 2009 & 12,5 & Daire & 13 & 5 & 1034 & Susuz & Yeni & & 37.80253422 & 33.56690733 & 3 small_s \\
\hline 179 & 172 & Seyithaci Obrugu-IX & Karapinar & Seyithaci Y. & 2012 & 11,2 & Daire & 16 & 0.5 & 1016 & Susuz & Yeni & & 37.80721675 & 33.57029599 & small_te \\
\hline 283 & 279 & Seyithaci Obrugu-VIII & Karapinar & Seyithaci Y. & 2009 & 11,8 & Daire & 3 & 2 & 1010 & Kapatilmis & Yeni & & 37.81582775 & 33.57890699 & small_te \\
\hline 180 & 173 & Seyithaci B. Kuru Obruk & Karapinar & Seyithaci Y. & Eski Olusum & 10,2 & Elips & $80 \_55$ & 5 & 1002 & Susuz & Eski & & 37.80721675 & 33.58057399 & small_yy \\
\hline 181 & 174 & Seyithaci K. Kuru Obruk & Karapinar & Seyithaci Y. & Eski Olusum & 10,25 & Elips & $48 \_42$ & 4 & 1000 & Susuz & Eski & & 37.80749475 & 33.58112899 & small_ys \\
\hline 177 & 170 & Sigacik Kuru Obruk & Karapinar & Sigacik Y. & Eski Olusum & 26,5 & Elips & $45 \_55$ & 11 & 1060 & Susuz & Eski & & 37.92832777 & 33.47112902 & 2small_y \\
\hline 199 & 240 & Tutal Obrugu & Karapinar & Simnik Mevkii & 2009 & 20 & Daire & 13 & 2 & 1010 & Susuz & Yeni & & 37.58555078 & 33.39696195 & 5 small_re \\
\hline 282 & 278 & Tahtali Obrugu & Cumra & Tahtali & Eski Olusum & 63,2 & Elips & 215_175 & 24 & 1442 & Susuz & Eski & & 37.28805094 & 32.40612895 & 5 small_ys \\
\hline 130 & 121 & Uc Obruk-II & Karapinar & Uc Obruk Mevkii & Eski Olusum & 13 & Daire & 209 & 12 & 1072 & Susuz & Eski & & 37.81368466 & 33.50021996 & small_ys \\
\hline 131 & 122 & Uc ObrikeII & Karaninar & Uc Obruk Movkii & Eski Olusum & 13,1 & Daire & 11 & 5 & 1060 & Susurz & Eoki & & 37.81420418 & 33.40054738 & small , \\
\hline
\end{tabular}

Şekil 3. Google Fusion Tables tablo yapısı

\subsubsection{Uygulama Arayüzü}

Obruk envanter bilgi sistemi ara yüzünün oluşturulması ve yönetimi için HyperText Markup Language (HTML), Cascading Style Sheets (CSS) ve JavaScript (JS) olmak üzere üç ana teknoloji kullanılmıștır. $\mathrm{Bu}$ teknolojilerin bir veya daha fazlasını uygulayan birçok web geliştirme çerçevesi, kütüphanesi ve eklentisi bulunmaktadır. Ara yüz gerçekte bir web sayfasıdır ve bu üç teknoloji web sayfası ve uygulamaları geliştirmede olmazsa olmaz bileşenlerdir. Aşağıda bileşenler detaylandırılmış, ayrıca sistemin içerdiği diğer bileşenler de listelenmiştir. 
HTML - Web sayfasının meta verisini, elemanlarını ve özniteliklerini belirleyen, internet tarayıcılarında düzgün olarak görüntülenmelerini sağlayan bir standart ișaretleme dilidir.

CSS - Web sayfasının ve barındırdığı elemanların sayfadaki yerleşimi, sıralaması ve tasarımlarını belirleyen dildir.

JavaScript - Web sayfalarının ve elemanlarının nasıl davranması gerektiğini belirleyen, web geliştiricileri tarafından standart olarak kabul görmüş programlama dilidir.

Bootstrap (http://getbootstrap.com) - İyi tasarlanmış form öğeleri (veri girdi alanları, düğmeler) ve kalıp pencereleri uygulayarak uygulamanın grafiksel kullanıcı arayüzünün (Graphical User Interface-GUI) stilini, düzenini ve yanıt vermesini basitleştirir. Ayrıca içeriği yeniden boyutlandırarak kullanıcının tarayıcı boyutuna göre, pencere alanını uygun bir şekilde doldurmaktadır.

jQuery (https://jquery.com) - Bir kullanıcının uygulamanın etkileşimine tepki göstermek ve içeriğini buna göre güncellemek için gereken programlamayı basitleştiren işlevler sağlar. Ayrıca, kullanıcının tarayıcısı (istemci) ile Asynchronous JavaScript ve XML (AJAX) kullanarak gerçekleşen uygulama sunucusu arasındaki iletișimin çoğunu kolaylaștırır.

Google Map API - Google firmasının 2005 yılı Haziran ayında, geniş spektrumlu programlama düzeylerine bağlı olarak farklı veri ve yazılımları farklı uygulamalar için eşleştirme ve bir araya getirme imkânı sunan ara yüzüdür. Kullanıcılar bu ara yüzü kullanarak Google Haritaları, kendi web sayfalarına ekleme ve düzenleme imkânı bulabilmektedir.

Google Fusion Tables API - Fusion Tables API ile web sayfasına eklenen Google haritaları üzerinde bir katman olarak eklenebilmektedir. $\mathrm{Bu}$ sistem ile kullanılan veri web sayfası kaynağında görüntülenmez. Web sayfasına eklenecek basit bir JavaScript kodu ile hazırlanan Fusion Table ID numarası kullanılarak bu tablonun herhangi bir kolonuna sorgu gerçekleştirilebilmekte, ihtiyaç duyulduğunda veri belirli bir kritere göre filtrelenebilmektedir. Ancak bazı veriler (örn. raster) bu tablolar aracılığıyla eklenemez. Ayrıca ücretsiz kullanım koşulları kapsamında belirli kısıtlamalar mevcuttur. Bu kisitlamalar;

$\checkmark \quad 25,000$ sorgu/gün,

$\checkmark$ 250MB tablo bașına alan,

$\checkmark$ Fusion Tables her bir hücresindeki veri maksimum 1 milyon karakteri desteklemektedir,

$\checkmark \quad$ Insert Limitleri

$\checkmark \quad$ Tek bir http sorgusu için maksimum veri boyutu 1MB ile sinırlıdır.

$\checkmark \quad$ Eklenecek tablo hücrelerinin toplam sayısı 10,000 hücredir.

$\checkmark$ Tek bir sorgu maksimum 500 INSERT ifadesi içerebilmektedir. $\checkmark$ Tablodaki sadece ilk 100,000 kayıt haritalanabilmektedir ya da mekânsal sorgu sonuçlarında gösterilebilmektedir,

$\checkmark$ Her bir harita için maksimum 5 katman eklenebilir

şeklindedir. Ayrıca nesnelere uygulanan stiller ve renklendirmeler Fusion Tables içeriği ile sınırlıdır. $\mathrm{Bu}$ sınırlamanın sebebi büyük boyutlu tablolarda bulunan verilerin web sayfasında görüntülenirken performansının yüksek olması amacıyla sunucu tarafından işlenmesidir. Google tarafından hazırlanan 200'ü așkın nokta stili Şekil 4'de gösterilmektedir. Her bir stilin Google tarafindan tanımlanmış bir adı bulunmakta ve bu adlar kullanılarak tablodaki noktalara stil tanımlanabilmektedir.

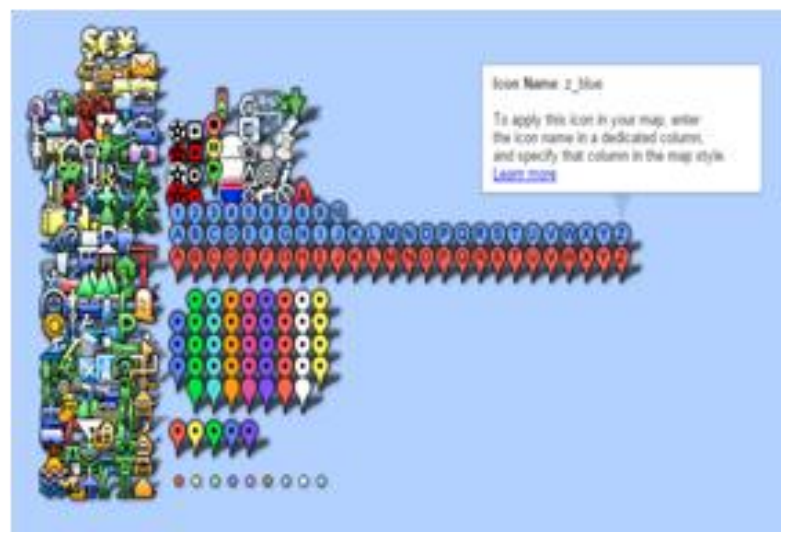

Şekil 4. Google Fusion Tables standart nokta stilleri

Obruk envanter bilgi sistemi ara yüzü tam boy altlık harita (Google Haritalar) imleç koordinatları ve anlık yakınlaştırma seviyesini gösteren bölüm, çalışma bölgesine odaklanan ve tüm katmanları kaldıran uygulama düğmeleri, temel katmanların haritaya eklenebilmesi için katman menüsü, obruk katmanı yoğunluk haritası ve özelliklerinin kontrol edildiği bölüm ve bölgeyle ilișkili ek katmanların haritaya eklenebileceği ikinci bir katman menüsünden oluşmaktadır (Şekil 5). GFT ile harita üzerine katman olarak eklenen mekânsal objelere ait öznitelik bilgileri, bilgi pencereleri şeklinde seçilen objeye ait olarak gösterilebilmektedir. $\mathrm{Bu}$ bilgi pencerelerine resim dosyaları, GFT tablolarındaki alanlar ve bağlantı linkleri eklenebilmekte ve özelleștirilebilmektedir (Șekil 6).

GFT kullanılarak interaktif haritaların Google Maps altyapısı üzerinde oluşturulabildiği ve gerektiğinde GFT'lerin kişisel web tabanlı uygulamalarda Google Haritalar üzerine katman olarak eklenebildiği daha önce ifade edilmiștir. GFT kullanılarak oluşturulan haritalarda kullanılabilen diğer kullanışlı bir özellik ise yoğunluk haritalarının oluşturulabildiği "heatmap" özelliğidir. Bu özellik kullanılarak nokta verilerinin anlık zoom seviyesine göre, kullanıcı tarafından belirlenen bir yarıçap parametresi dahilinde gruplandırılarak yoğunluk haritası şeklinde gösterimi mümkün olmaktadır. 


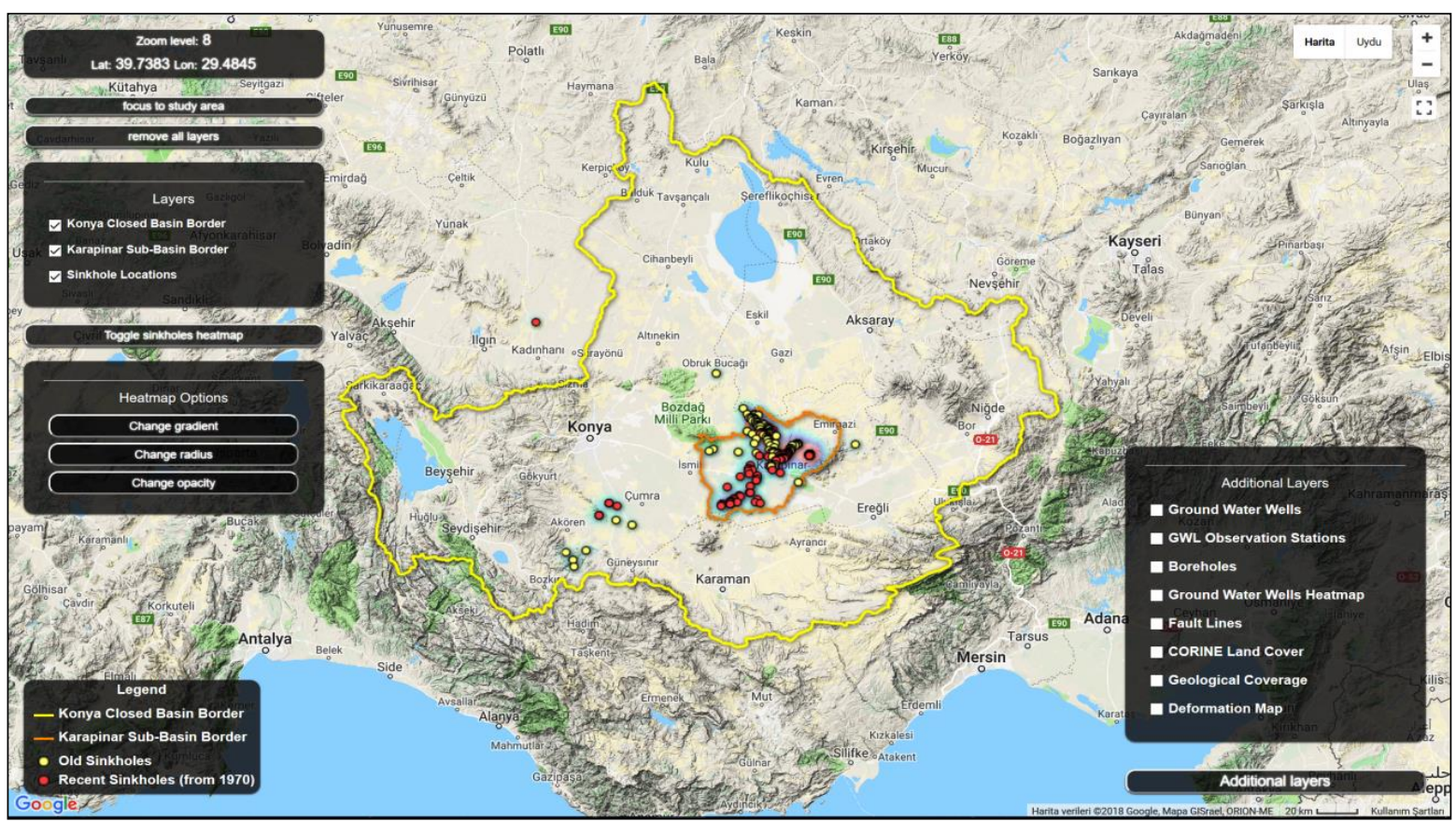

Şekil 5. Obruk envanter uygulama arayüzü

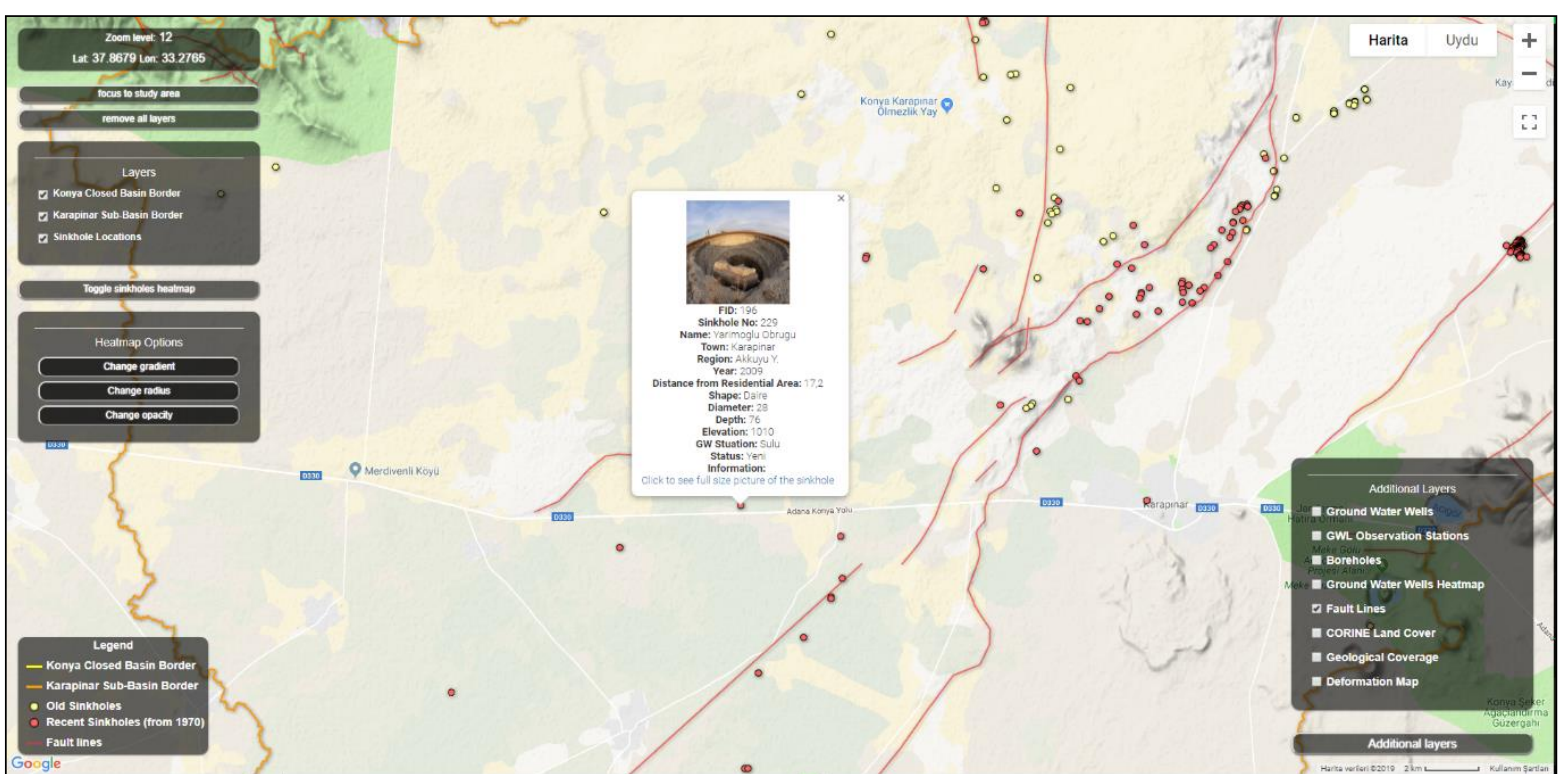

Şekil 6. Öznitelik bilgilerinin Google Maps Info Vindow özelliği ile görüntülenmesi

GFT ile kullanılabilen dosya türleri arasında Google şirketinin haritalama servislerinde kullandığı Keyhole Markup Language (KML) formatı da bulunmaktadır. $\mathrm{Bu}$ format kullanılarak nokta geometri tipinde olmayan mekânsal objeler de veri tabanına eklenebilmektedir. Örneğin çalışmada kullanılan fay hatları ve çalışma bölgesi sınırı çizgi tipindedir ve bu verinin GFT ile kullanılabilmesi için KML formatı kullanılmıștır. Aynı işlem alan geometri tipindeki objeler için de uygulanmıștır. Şekil 7'de nokta, çizgi ve poligon tipindeki verilerin eş zamanlı gösterimi verilmiștir. 


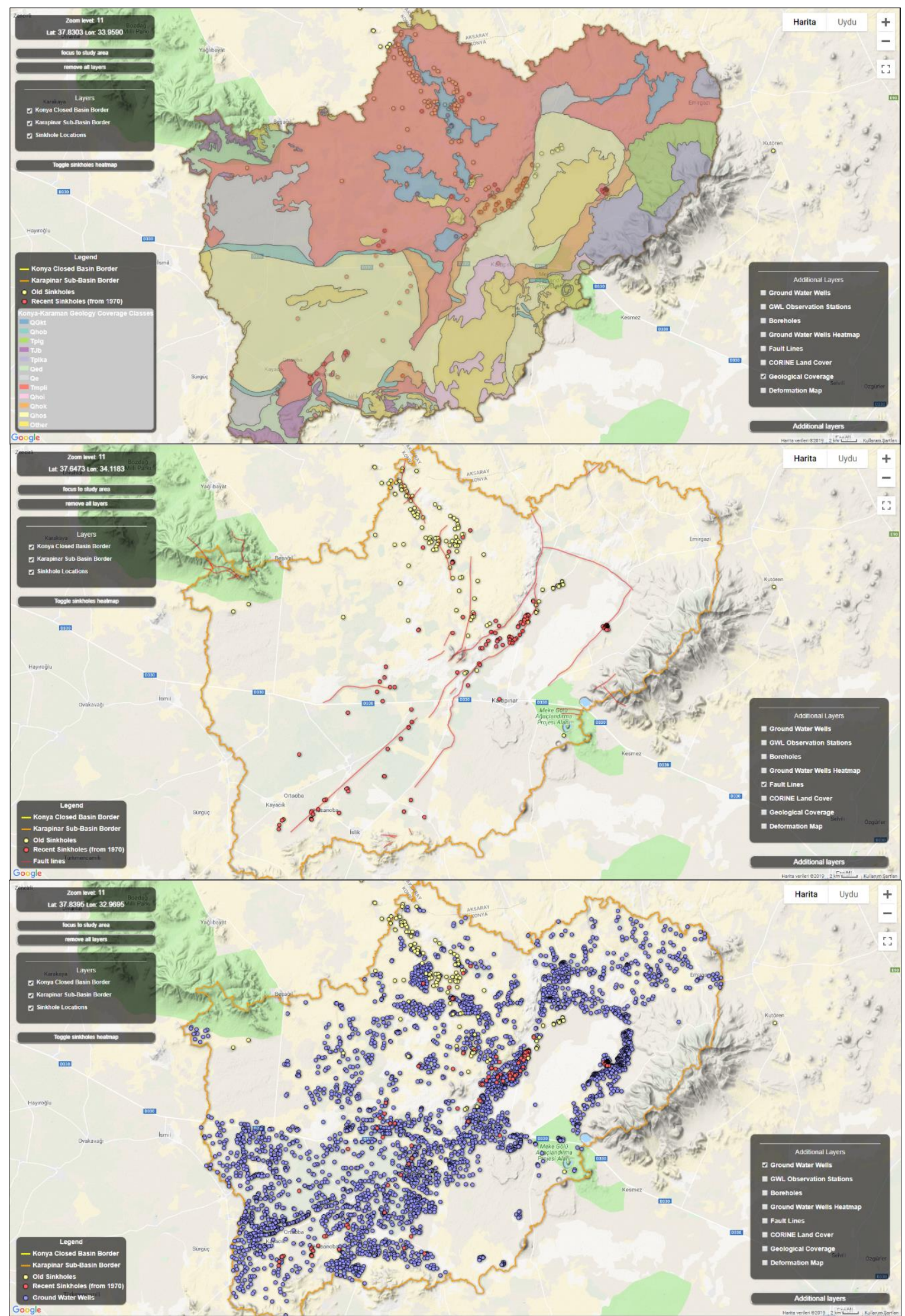

Şekil 7. Harita üzerine eklenen katmanlar ve bu katmanlara ait bilgilerin lejant penceresine eklenmesi (üst: jeoloji haritası, orta: fay, alt: sulama kuyuları). 
Obruk envanter sistemi için oluşturulan uygulamada, harita üzerine eklenen her bir katman için otomatik olarak gösterilen bir lejant penceresi de oluşturulmuştur. Kullanıcı haritaya bir katman eklediğinde sadece o katmana ait bilgi lejant üzerinde gösterilmektedir (Şekil 7). Google haritalar farklı harita türlerini kullanmayı da mümkün kılmaktadır. Bunlar arasında uydu görüntüleri, yol haritaları ve topoğrafik haritalar bulunmaktadır. Şekil 8'da altlık harita olarak uydu görüntüsünün seçildiği görülmektedir.

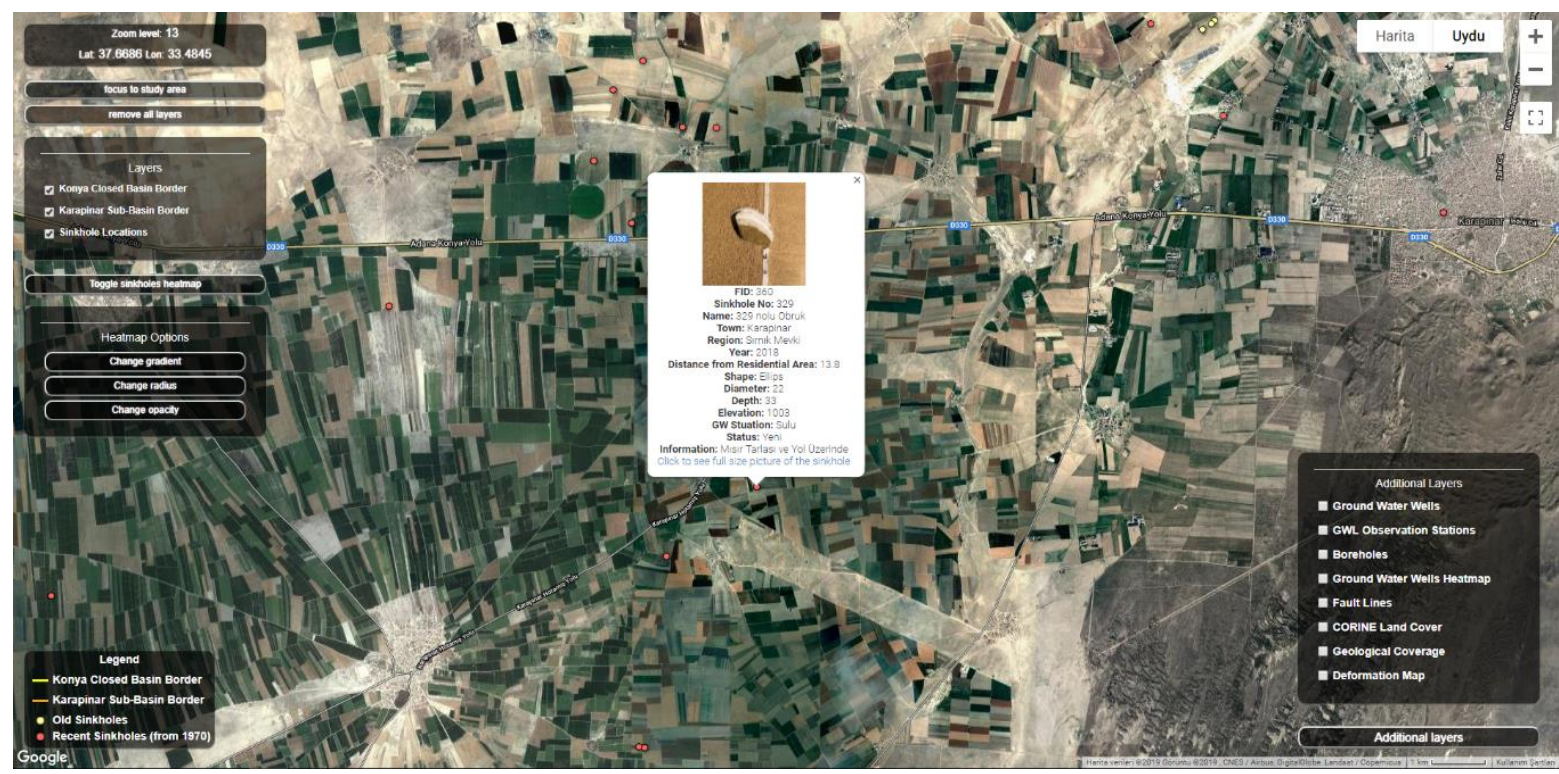

Şekil 8. 2018 eylül ayında olușan obruğa ait öznitelik bilgilerinin Google Maps uydu görüntüsü üzerinde Info window özelliği ile görüntülenmesi

Daha önce de belirtildiği üzere kurulan sistemde haritalama için Google Haritalar servisinin ve mekânsal verilerin depolanması ve yönetimi için Google Drive bulut teknolojisinin Fusion Tables servisinin kullanılmasının avantaj ve dezavantajları bulunmaktadır. Dezavantajları olarak Google tarafindan sunulan kisitlamalar verilebilmektedir. Bunlar genellikle kullanım kısıtlamaları olmayıp görüntüleme kısıtlamalarından oluşmaktadır.

Sistemin en önemli avantajları arasında ise özellikle verilerin bulut tabanlı bir depolama alanında tutulması nedeni ile veriye ulaşım, görüntüleme, ortak çalıșma, güncelleme ve paylaşım işlemlerinin tamamı için internet bağlantısının yeterli olması verilebilmektedir. Ayrıca güncellenen veri sonrası, harita üzerinde herhangi bir değişiklik ya da kodlamaya gerek kalmadan haritanın da güncellenmesi oldukça kullanışlı bir özelliktir. Bunun nedeni haritanın GFT ile canlı bir bağlantıya sahip oluşudur.

\section{SONUÇLAR ve TARTIŞMA}

Obruk envanter bilgi sisteminin oluşturulması kapsamında Konya Kapalı Havzası sinırları içerisinde 362 tane obruk oluştuğu tespit edilmiş fakat bunların sadece 332 tanesinin çalışma bölgesi (Karapınar ve çevresi) sınırları içerisinde oluştuğu belirlenmiștir. Sadece 2019 yılının ilk yarısında farklı derinlik ve çaplarda olmak üzere şubat ayında 6, nisan ayında 3, mayıs ayında 2 obruk meydana gelmiştir. 332 obruğun 21 tanesi ise tarımsal faaliyetlerin devam edebilmesi ve arazi değerlerindeki düşüşü önlemek amacı ile kapatılmıştır. Ayrıca bu 332 obruk arazi çalışması sırasında yapılan mülakatlar ve MTA'nın 2017 yılında yayınladığı ara rapordaki oluşum tarihleri dikkate alınarak eski ve güncel (1970 sonrası) oluşumlu obruklar olmak üzere 2 sinıfa ayrılmıştır (Törk ve ark., 2017).

Güncel obruklar 1970 yılından günümüze kadar olan süre zarfında oluşan obrukları kapsamaktadır ve bunların çoğunluğunun 2000 yılından sonra oluştuğu tespit edilmiştir. Tarih bilgileri bölge halkı ile yapılan mülakatlar sonucu öğrenilmiștir. Bölgede oluşan obruklara ait herhangi bir oluşum raporu tutulmaması, bölgedeki çoğu obruğa ait oluşum tarihleri bakımından bilgi eksikliğine neden olmaktadır.

Bu çalıșma kapsamında elde edilen 362 obruğa ait envanter bilgisi gelecekte gerçekleştirilecek tehlike, risk ve planlama çalışmalarında destek veri olarak kullanılması planlanmaktadır. Ek olarak, bu envanter verisinin ilgili kişi ve kurumlar ile web tabanlı bir sistem vasıtasıyla paylaşılması planlanmaktadır. Coğrafi Bilgi Sistemi (CBS) işlevselliği sunabilecek bir web uygulaması, Google firmasının ücretsiz hizmetleri olan Google Maps ve veri depolama ve yönetimi için oluşturduğu Fusion Tables hizmetleri kullanılarak olușturulmuștur. Oluşturulan web uygulamasının altyapısı HTML5, CSS3, JavaScript, Google Maps API V3 ve Google Fusion Tables API teknolojilerini içermektedir. Bu teknolojilerin kullanılmasıyla, bir web sayfası içerisine Google haritaları eklenerek, mekânsal verilerin Fusion Tables içerisinde depolandığı ve 
Google haritalar üzerinde bir katman olarak görüntülenebildiği etkili harita "Mashup" uygulaması olușturulmuștur.

Her ne kadar kullanışlı araçlar olsa da bu gibi platformlar her zaman platformu sunan şirketlerin kararlarılya şekillenmektedir. Bu çalışmada bulut depolama alanının coğrafi veriyi depolamak ve yaymak açısından kullanılabilirliği ele alınmış ve örneklenmiştir. En iyi çözüm olmasa da burada ele alınan yaklaşımın oldukça kolay ve pratik olduğu düşünülmektedir. Gelecekte bu hizmetlerin devam edip etmeyeceği belirsizliğini korusa da, çevrimiçi sunulan birçok hizmette aynı durum söz konusudur.

Obruk Envanter Haritaları, bölgesel ölçekli obruk duyarlılık, olası tehlike ve risk değerlendirmelerinin temel girdi parametresini oluşturmaktadır. $\mathrm{Bu}$ çalışmada üretilen Obruk Envanter Haritasının uygun yaklaşımlar ile kullanılması durumunda Konya Kapalı Havzası genelinde obruk risk yönetimi ve zarar azaltma çalışmalarında gittikçe artan yaygın etki yaratacağı düşünülmektedir.

\section{KAYNAKÇA}

Agrawal, D., Das, S., \& El Abbadi, A. (2011). Big data and cloud computing: current state and future opportunities. Paper presented at the Proceedings of the 14th International Conference on Extending Database Technology.

Awange, J. L. (2012). Environmental monitoring using GNSS: Global navigation satellite systems: Springer Science \& Business Media.

Covili, J. J. (2016). Going Google: Powerful tools for 21st century learning: Corwin Press.

Crawley, S., Ames, D., Li, Z., \& Tarboton, D. (2017). HydroShare GIS: Visualizing Spatial Data in the Cloud. Open Water Journal, 4(1), 2.

Galloway, D. L., \& Burbey, T. J. (2011). Regional land subsidence accompanying groundwater extraction. Hydrogeology Journal, 19(8), 14591486.

Haselmann, T., Thies, G., \& Vossen, G. (2010). Looking into a REST-based universal API for Databaseas-a-Service systems. Paper presented at the Commerce and Enterprise Computing (CEC), 2010 IEEE 12th Conference on.

Ilarri, S., Mena, E., \& Illarramendi, A. (2010). Location-dependent query processing: Where we are and where we are heading. ACM Computing Surveys (CSUR), 42(3), 12.

Mell, P., \& Grance, T. (2010). The NIST definition of cloud computing. Communications of the ACM, 53(6), 50.
Miller, M. (2008). Cloud computing: Web-based applications that change the way you work and collaborate online: Que publishing.

Stonebraker, M. (2010). SQL databases v. NoSQL databases. Communications of the ACM, 53(4), 10-11.

URL-1. Google Fusion Tables API Retrieved 16.01.2018, from https://developers.google.com/fusiontables/d ocs/v1/getting started

Vaquero, L. M., Rodero-Merino, L., Caceres, J., \& Lindner, M. (2008). A break in the clouds: towards a cloud definition. ACM SIGCOMM Computer Communication Review, 39(1), 5055.

Zhang, D., Liu, Y., Liu, A., Mao, X., \& Li, Q. (2017). Efficient path query processing through cloudbased mapping services. IEEE Access, 5, 1296312973. 